\title{
Research on the Process Optimization of the Production Plan in Multiple Variety and Small Lot Production Enterprise
}

\author{
Honghai Chen*, Yanru Zhang and Mingwen Li
}

Hefei University of Technology, Anhui, Hefei, China

\begin{abstract}
Aiming at the enterprise with multiple variety and small lot production, based on the production plan from ERP, the monthly shipment amount can be predicted by designing and optimizing the related factors properly. The economic lot-size, the safety stock, the production interval and the production load evaluation are used in the decision of the production plan effectively, which makes the execution of the production plan accurate and makes the resources utilized efficiently.
\end{abstract}

Keywords: Economic lot-size, process optimization, production plan, safety stock.

\section{INTRODUCTION}

With the diversification of the demand, multi variety and small batch production has become a norm in business. However, due to the effect of the economic lot-size, the safety stock, the production interval and the production load evaluation, the execution of the production plan needs to adjust the plan with a lot of efforts. Especially, when the load of production plan is very high, this adjustment is not only complex, but also the vast data makes the adjusted data inaccurate easily. This paper, combining the real condition of the enterprise, proposes a modified process of making production plan of some vehicle's parts production enterprise to optimize the ERP and improve the production plan the rationality and accuracy.

\section{THE ANALYSIS OF THE CURRENT PRODUC- TION PLAN PROCESS}

\section{1. The Process of Making Production Plan}

After the sales department gets the demand information from the main engine plants every week, the requirement plan is built based on the current stock and this plan will send to the manufacture department. Then, the manufacture department analyzes the productivity preliminary to determine the production task of this week. After that, combing the current raw material, the semi-product stock, BOM, the product manufacturing cycle, the safety period of the adjacent procedures, the productivity analysis sheet, weekly production plan and the purchasing list, the daily production plan is established. The process is shown in Fig. (1).

\subsection{The Problem During Making Production Plan}

1) The problem of manual operation. The production plan is made still with the aid of artificial, which is the waste of human resource and makes errors easily, even omits the product causing over the due date.

2) The producing activity lacks plan and rules. The sales department generates the weekly production plan based on the net plan of the main engine plants, which makes the lack of the overall production plan because sometimes the sales department needn't ship the products every week or sometimes the production department cannot produce every week. Then, in one month, the production load is very high in some week, while the load is very low in other weeks.

3) The economic lot-size is inaccurate. Now, the lot-size of some parts is determined by the experience of the production department, which is constant. As the decision of the lotsize has a great effect on the production cost, the lot-size should be updated by the change of the marketing environment.

4) The static safety stock is not reasonable. The sale of the vehicle's parts has obvious seasonal characteristics. The static safety stock makes the off-season inventory backlog, so as to take up a lot of money. In the in-season, the lack of safety stock generates the risk of a temporary increase of the production plan, which disturbs the normal order of production and the additional overtime costs, even cause that the department cannot deliver the goods on time and affect the credibility of the enterprise.

5) The productivity analysis is inaccurate. The production department analyzes the weekly productivity based on the 8-hours production amount of single variety. However, the productivity analysis should be specific to each device and human and other resources of production. In the reality, the productivity analysis is often not accurate enough.

\section{THE MODIFICATION AND THE OPTIMIZATION OF THE PROCESS OF THE PRODUCTION PLAN}

\subsection{The Modification Framework of Production Plan}

The problem of the current process which needs to be solved is realizing the automation during making production 


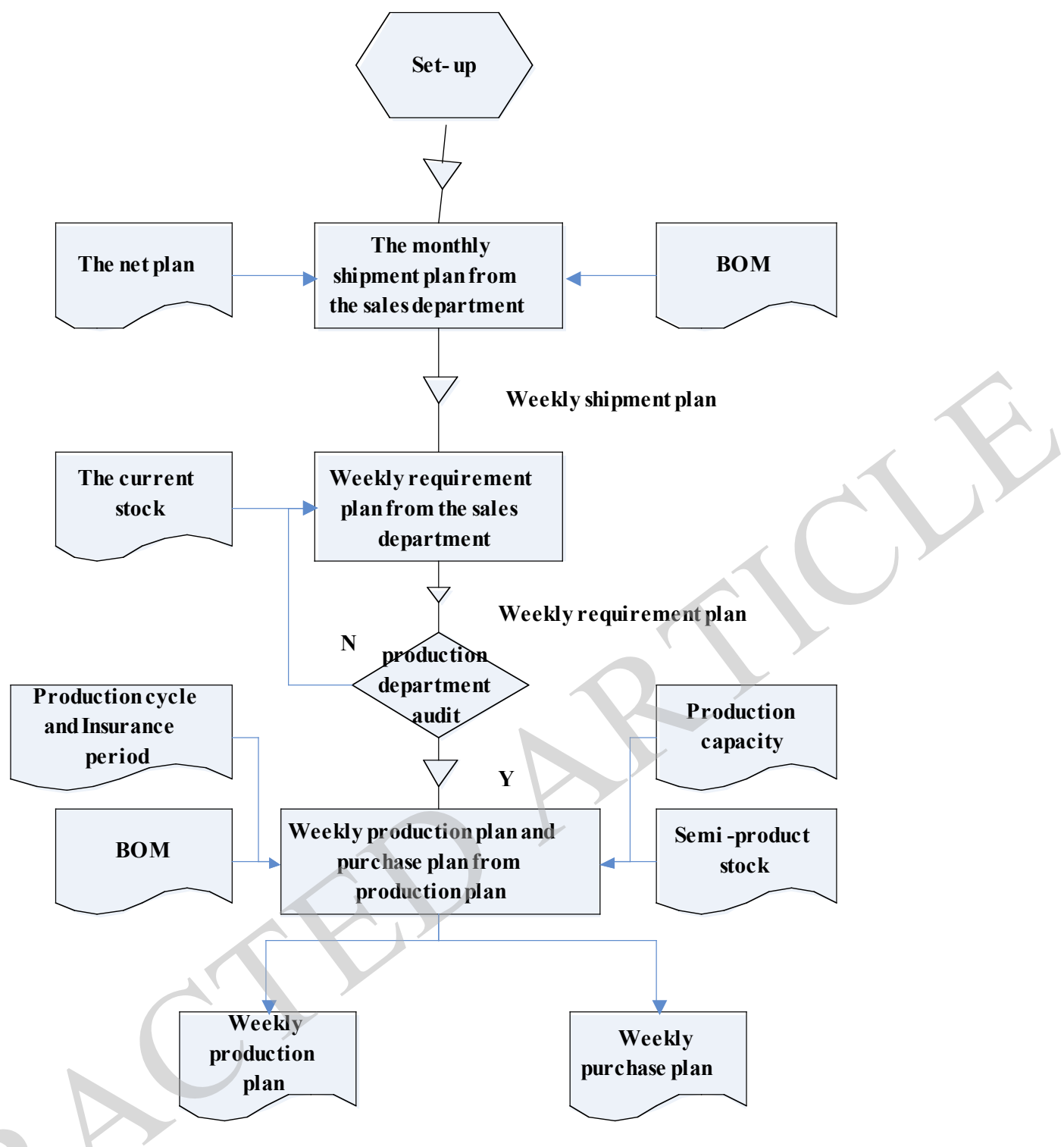

Fig. (1). The process of making the production plan.

plan of ERP. Then, the ERP needs to provide a port. According to this port, the execution rules of the system are reset to adjust the related data in changing marketing environment.

Firstly, the four parameters of ERP- monthly requirement amount, economic lot-size, safety stock and the production interval -need to be updated. After updating these parameters, the system will generate a raw monthly requirement plan which is used to allocate the production resources for guiding how to make the weekly requirement plan.

The sales department gets the weekly production plan from the main engine plants and imports it to ERP. Then, ERP generates the weekly requirement plan automatically based on the BOM, economic lot-size and safety stock; while the sales department checks this requirement plan and sends it to the production department. By importing the requirement plan to ERP system, ERP system schedules the production based on BOM, intelligent scheduling production cycle and the safety period of the adjacent procedures. This schedule should adjust the capability-lack procedures according to the evaluation of each device. The adjustment rule is: make sure the products with due date deliver to warehouse on time. To the product which cannot be adjusted, extend the due date or purchase it by negotiating with the planner from the sales department. Finally, enter the executed weekly requirement plan to ERP. The framework is shown in Fig. (2).

\subsection{The Determination of the Next-Month Shipment Amount based on the Demand Prediction Model}

The demand analysis is to plan the production amount of the products for the next month according to the demand prediction of the products. The specific procedure is to read the shipment amount of each product in recent 10 months, then to do prediction analysis by using expert consulting [1], moving average method [2], grey forecasting model GM (1, 1) [3], at last to obtain the predicted demand amount by using mixed optimization model.

Take a rear support bracket plant as an example. The shipment amount of the rear support bracket during from Jan. 2013 to Oct. 2013 is shown in Table 1. 


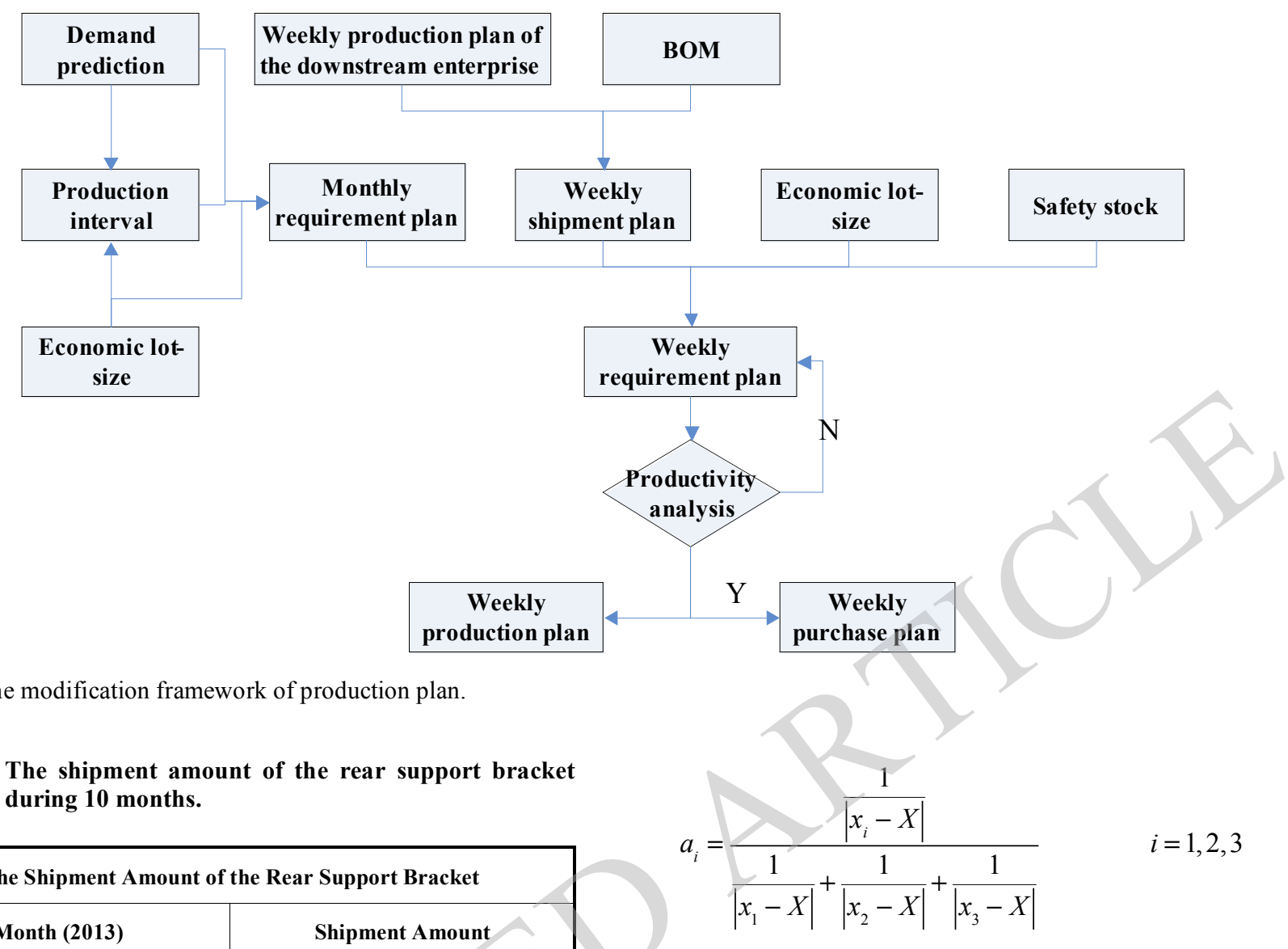

Fig. (2). The modification framework of production plan

Table 1. The shipment amount of the rear support bracket during 10 months.

\begin{tabular}{|c|c|}
\hline \multicolumn{2}{|c|}{ The Shipment Amount of the Rear Support Bracket } \\
\hline Month (2013) & Shipment Amount \\
\hline 1 & 53228 \\
\hline 2 & 31861 \\
\hline 3 & 50544 \\
\hline 4 & 47783 \\
\hline 5 & 42341 \\
\hline 6 & 20643 \\
\hline 7 & 27410 \\
\hline 8 & 38206 \\
\hline 9 & 36694 \\
\hline 10 & 28230 \\
\hline
\end{tabular}

The results of the predicted shipment amount for the next month are 30000, 23106, 29065 by expert consulting, moving average method, grey forecasting model GM $(1,1)$ respectively.

The important point of the mixed optimization is to determine the weight of three models above. The weight of each model is obtained by the gap between the predicted amount by the model and the realized amount.

Suppose, the predicted amounts of three models are $\mathrm{x} 1, \mathrm{x} 2, \mathrm{x} 3$ and the realized amount is $\mathrm{X}$. Then, the weight of the ith model is:
If the realized amount of the rear support bracket plant in Nov. 2013 is 30437, then the weights of three models (expert consulting, moving average method, grey forecasting model) are $a_{1}=0.7256, a_{2}=0.04326, a_{3}=0.2311$, respectively when predicting the shipment amount for Dec.

After the determination of the data in Nov., the weights of three models can be obtained. Then, using the same method, the predicted amounts for Dec. of three models are 25000, 29935, 25079, respectively.

Using the calculation of the mixed optimization model, the integrated predicted amount is 25231.7 . The realized amount is 25225 in Dec. The error is $0.0265 \%$.

According to the calculation result, the error of the expert consulting and the grey forecasting model is small, while the error of moving average method is big. Hence, the error of the mixed optimization is much small by allocating the weights of three models.

\subsection{The Determination of Economic Lot-Size by using Activity Based Costing(ABC)}

We must start from the several factors which influence the cost when determining the economic lot-size. The factors are the production cost, set-up cost, stock cost and shortage cost which are considered in the traditional ERP. The rule of it is to minimize the total cost. This paper adopts $\mathrm{ABC}$ method [4] by combining the real condition of the enterprise to analyze the set-up $\operatorname{cost} C_{1}$, the stock $\operatorname{cost} C_{2}$ and the shortage $\operatorname{cost} C_{3}$, then to obtain the total cost [5] by taking the production in Dec. of the plant as an example. 


$$
\begin{gathered}
C=C_{1}+C_{2}+C_{3}=\frac{D}{Q} *\left(B_{11}+B_{12}\right)+\left(B_{21}+B_{22} * P\right) * \\
(m-r)\left(\frac{Q}{m}\right)^{2} / T_{1}+\frac{D}{Q} * A_{32} * q
\end{gathered}
$$

According to the production department inquiry and research, obtained data is shown in the following Table 2. Here production cycle time $T_{1}$ is $T_{1}=Q / m$.

Table 2. The value of the related parameters.

\begin{tabular}{|c|c|}
\hline Name & Value \\
\hline \hline production amount per unit time $\mathrm{m}$ & 200 \\
\hline consumed production amount per unit time $\mathrm{r}$ & 190 \\
\hline order amount D & 53228 \\
\hline set-up cost per time B11 & 40 Yuan \\
\hline detection cost per time B12 & 6 Yuan \\
\hline space cost per time B21 & 20 Yuan \\
\hline depletion cost per product B22 & 20 Yuan \\
\hline product loss rate $\mathrm{x}$ & $1 \%$ \\
\hline shortage cost per time A32 & 150 Yuan \\
\hline shortage probability $\mathrm{q}$ & $5 \%$ \\
\hline
\end{tabular}

Use Lingo11 to solve the problem above. The result is: the economic lot-size $\mathrm{Q}=1679$, the cost $\mathrm{C}=3391$ Yuan. Taking the production in Jan. 2013 as an example, the constant lot-size $\mathrm{Q}=2500$, the cost $\mathrm{C}=5084$ Yuan. By $\mathrm{ABC}$ method, the saved cost is 1693 Yuan.

\subsection{The Application of Dynamic Safety Stock}

Only in terms of cost, the safety stock setting should be integrated into the holding cost, shortage cost to seek out a best value which minimizes the total cost [6]. Aiming at this plant, an insurance period should be set first, and the stock should satisfy the demand in the insurance period.

The formula of dynamic safety stock is:

$$
y=a t=\frac{R}{T} t
$$

where, $\mathrm{y}$ is the safety stock, a is the average shipment amount per day in one period, $\mathrm{R}$ is the total shipment amount in one period, $\mathrm{T}$ is cycle time and $\mathrm{t}$ is the insurance period.

The dynamic safety stock is set by month and the parameter of this stock is total production amount $\mathrm{R}$ and the insurance period $t$ [7].

\subsubsection{The Safety Stock}

Divide the products into three categories: A, B, C. The features of three categories are shown in Table 3.

Use A. infusing loving method to obtain the weight of each evaluation item by taking the production in Dec.2013. The relation matrix is shown in Table 4.

After calculating the weight of each evaluation item, the evaluation of A, B, C can be obtained by the same method where the storage space of per rear support bracket is $0.4 \mathrm{~m}^{*}$ $0.4 \mathrm{~m} * 0.2 \mathrm{~m}$ and the shipment in Dec. 2013 is 25225 which is not easily damaged. The details are shown is Table $\mathbf{5}$.

According to Tables $\mathbf{4}$ and $\mathbf{5}$, the integrated of three product categories is calculated, which is shown is Table $\mathbf{6}$.

From Table 6, because the integrated evaluation value of A is biggest, the rear support bracket is classified as A. Let $\mathrm{t}=3-4$ days, $\mathrm{T}=23$ days, and $\mathrm{R}=25225$. The safety stock of the rear support bracket in Dec. 2013 [8]:

$$
\frac{25225}{23} *(3 \sim 4)=3290 \sim 4387
$$

The lower bound of the safety stock is 3290 and the upper bound is 4387 .

Table 3. The features of product category.

\begin{tabular}{|c|c|c|c|c|}
\hline Category & Storage Space & $\begin{array}{c}\text { Shipment Amount Per } \\
\text { Month }\end{array}$ & Damaged & Insurance Period (day) \\
\hline \hline A & small & big & easy & $3-4$ \\
\hline B & fair & fair & fair & $4-6$ \\
\hline C & small & small & static & $6-8$ \\
\hline
\end{tabular}

Table 4. The relation matrix table.

\begin{tabular}{|c|c|c|c|c|}
\hline No. (j) & Evaluation Item & $\mathbf{R}_{\mathbf{j}}$ & $\mathbf{K}_{\mathbf{j}}$ & $\mathbf{W}_{\mathbf{j}}$ \\
\hline \hline 1 & Storage space & $0.5+2$ & 0.286 \\
\hline 2 & shipment amount & 4 & 0.571 \\
\hline 3 & damaged easily & - & 0.143 \\
\hline
\end{tabular}


Table 5. $\quad V_{\mathrm{ij}}$ by A. infusing loving method.

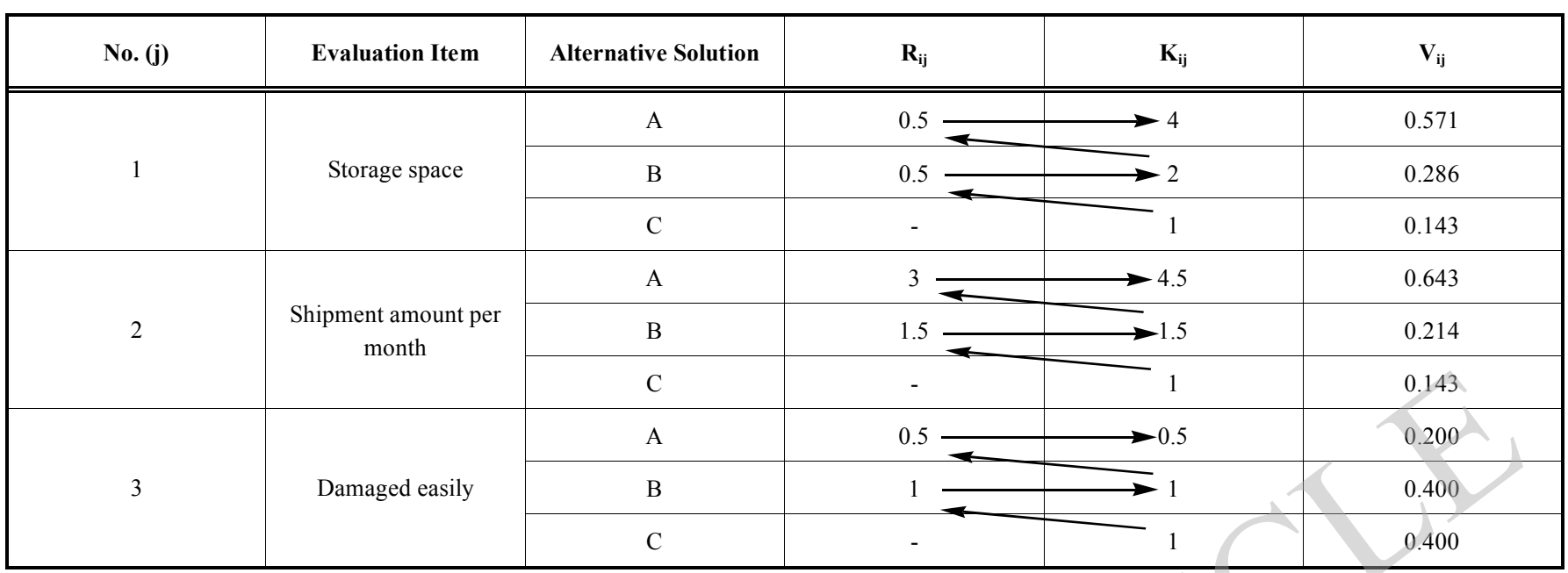

Table 6. The integrated table.

\begin{tabular}{|c|c|c|c|c|}
\hline \multirow{2}{*}{$\begin{array}{l}\mathbf{A}_{\mathbf{i}} \\
\mathbf{V}_{\mathbf{i j}} \\
\mathbf{w}_{\mathbf{j}}\end{array}$} & Storage Space & $\begin{array}{c}\text { Shipment Amount Per } \\
\text { Month }\end{array}$ & Damaged Easily & \multirow{2}{*}{$\mathbf{V}_{\mathbf{i j}}$} \\
\cline { 2 - 5 } $\mathbf{x}_{\mathbf{j}}$ & $\mathbf{0 . 2 8 6}$ & $\mathbf{0 . 5 7 1}$ & $\mathbf{0 . 1 4 3}$ \\
\hline \hline $\mathrm{A}$ & 0.571 & 0.643 & 0.200 & 0.559059 \\
\hline $\mathrm{B}$ & 0.286 & 0.214 & 0.400 & 0.261190 \\
\hline $\mathrm{C}$ & 0.143 & 0.143 & 0.400 & 0.179751 \\
\hline
\end{tabular}

\subsubsection{The Advantage of the Dynamic Safety Stock}

The dynamic safety stock is updated according to the changes of the related parameters the end of a month. Compared to the static safety stock, the dynamic one can handle the difference of the stock in in-season and off-season. On the other hand, the factors which influence the safety stock are changeable. For example, in certain period, because the product stock space is limited, which causes the increase of the weight of the storage space, decrease the safety stock properly.

\subsection{The Optimization Process of Production Plan}

\subsubsection{The Generation of the Requirement Plan}

The conditions of generating the requirement plan are the predicted shipment amount, the economic lot-size, the production interval and the safety stock.

1. The determination of the production interval

The formula of the production interval [4] is:

$$
R=Q / n_{d}=Q /(P / T)=Q * T / P
$$

where, $\mathrm{R}$ is the production interval, $\mathrm{Q}$ is lot-size, $n_{d}$ is average production amount, $\mathrm{T}$ is the production cycle, $\mathrm{P}$ is the instock amount.

The in-stock amount of the rear support bracket in Jan. 2013 is 56412 and the production interval is 0.77 day, which means that the plant is in the continuous production condition.
2. The generation of the monthly requirement plan

The monthly requirement plan is the raw plan of the production categories and the amount per week in the next month, which can balance the production capability in one month to make sure delivery on time and production cost decreased. Referencing the production interval, divide the predicted shipment amount in one month into each week. As shown in Table 7, the stock is that in the beginning of the month, the safety stock is the lower bound of the stock, the requirement amount is the in-stock product amount which is the integral multiple of the lot-size.

Stock $=$ requirement amount + stock in last month- the shipment amount

Requirement amount $=$ shipment amount + safety stock stock in the beginning.

\subsubsection{The Adjustment of the Weekly Requirement Plan}

The weekly requirement plan generated by ERP should consider the net plan and the previous generated requirement plan. Firstly, the raw edition of the weekly requirement plan is generated according to the BOM, the current stock, the safety stock, the economic lot-size. Two factors need to be considered here. The first one is to consider the accordance between the weekly requirement plan and the monthly one, and the second one is to consider the difference between the production amount of the weekly and the monthly requirement plan. 
Table 7. The table of the month requirement amount.

\begin{tabular}{|c|c|c|c|c|c|}
\hline \multicolumn{7}{|c|}{ The Requirement Amount in May 2014 } \\
\hline Week & Shipment Amoune & Stock & Safety Stock & Lot-Size & Requirement Amount \\
\hline \hline 1 & 10581 & 2000 & 3000 & 1700 & 1700 \\
\hline 2 & 10581 & 3319 & 3000 & 1700 & 1900 \\
\hline 3 & 10581 & 2938 & 3000 & 3000 & 11900 \\
\hline 4 & 10578 & 4257 & & & 40200 \\
\hline Sum & 42321 & 3879 & & & 44200 \\
\hline
\end{tabular}

Table 8. The productivity analysis of the device.

\begin{tabular}{|c|c|c|c|c|c|c|}
\hline Device No. & $\begin{array}{c}\text { Device Model } \\
\text { No. }\end{array}$ & Device Name & Supplier & Serial Number & $\begin{array}{c}\text { Punch Times in } \\
\text { 8 hours }\end{array}$ & $\begin{array}{c}\text { Needed Punch } \\
\text { Times }\end{array}$ \\
\hline \hline 150 & JH21-80 & $\begin{array}{c}\text { 80T purchint } \\
\text { machine }\end{array}$ & $\begin{array}{c}\text { Wode Jingji } \\
\text { (China) Company }\end{array}$ & 12093 & 8000 & 9000 \\
\hline
\end{tabular}

Based on the modification of the weekly requirement plan, the final plan from ERP is sent to the production department. The planner import it to ERP to schedule smartly.

\subsubsection{The Productivity Analysis and the Adjustment of the Weekly Plan}

The productivity analysis is to consider if the production capability of a device can satisfy the production load in a certain period of time. Compare the punch times with the capacity of this punching machine. Decompose the weekly production plan into sub-plan on each procedure according to process flow chart. Then, determine the needed device for each procedure, the needed production capacity per product and the needed total production capacity.

After the decomposition of the weekly production plan, compare the total punch times and the rated production capacity in 8 hours of one device, which is shown in Table 8.

When the difference is negative, the system will notice and mark the related procedure. The planner of the production department will modify the weekly production plan based on the result of Table $\mathbf{8}$ until the production capacity is satisfied. If the difference is large, which causes extra working time irresoluble, then the planner of the production department needs to negotiate with the planner of the sales department to solve this problem by extending the due date or outsourcing. After the negotiation, the system generates the weekly procurement plan according to the determined weekly requirement plan. The details are not explained here.

\section{CONCLUSION}

This paper analyzes the problem in the process of making production plan, and then by adding the process of making monthly requirement plan, the monthly shipment amount is predicted. Using the economic lot-size, safety stock, production interval and the productivity analysis into the process of making production plan, a model of generating production plan automatically is established according to the reasonable allocation of the production resources. This model can achieve the goal of decreasing the production cost and increasing the productivity.

\section{CONFLICT OF INTEREST}

The authors confirm that this article content has no conflict of interest.

\section{ACKNOWLEDGEMENTS}

Declared none.

\section{REFERENCES}

[1] L. Wang, Y. Chen, and H. Ma, Production Planning and Control, Tsinghua University Press, China, 2007.

[2] L. Wang, Production Planning and Control, Machine Press, China, 2011.

[3] S. Liu, and N. Xie, Grey System Theory and its Application, Science Press, China, 2013.

[4] H. Li, Production Planning and Control, Science Press, 2005.

[5] T. Xia, and K. Xu, X. Hong, "Economic production on quantity model by activity-based costing," Industrial Engineering, vol. 12, no. 4, pp. 73-77, 2009.

[6] X. Jiang, and R. Zhang, "Safety stock setting of automobile accessory enterprises," Logistics Sci-Tech, vol. 10, pp. 23-26, 2008.

[7] Y. Wang, System Engineering, China Machine Press, China, 2003.

[8] E. Cardenas-Barron, L. Trevino-Garza, G. Widyadana, and G. Agus, "A constrained multi-products EPQ inventory model with discrete delivery order and lot size," Apppied Mathematics and Computation, vol. 230, pp. 359-370, 2014.

\footnotetext{
Received: September 16, 2014

Revised: December 23, 2014

Accepted: December 31, 2014

(C) Chen et al.; Licensee Bentham Open.

This is an open access article licensed under the terms of the Creative Commons Attribution Non-Commercial License (http://creativecommons.org/licenses/by-nc/3.0/) which permits unrestricted, non-commercial use, distribution and reproduction in any medium, provided the work is properly cited.
} 